\title{
The Usefulness of Therapeutic Jurisprudence for Re-thinking Babies in Prison
}

\author{
Author: Helen Crewe \\ Lecturer Nottingham Trent University \\ Helen.crewe@ntu.ac.uk \\ Fellow RSA, \\ Independent Researcher (no funds received)
}




\section{The Usefulness of Therapeutic Jurisprudence for Re-thinking Babies in Prison}

International human rights state that imprisonment for mothers with babies should be used as a last resort. Currently, there is no international agreement for the age limit of children in prison and a lack of consistency with the treatment of this minority population. Prison mother and baby units are presented as the solution in the majority of countries however, these living arrangements are not always in the best interests of children.

Currently babies are in prison as a consequence of the sentencing of their mother. The dominant understanding is that babies need to be with their birth mother for the first days of their lives. For example, a recent report from the United Kingdom explains the detrimental effects of separation for babies and advocates that prison policy makers should take this into account (Abbot, Scott, Thomas and Weston, 2020). Solutions to the complex problem of babies living in prisons are limited to what amounts to them continuing to live with their mothers in 'gentler, kinder, cages'. There is a need to 're-think' the existence of babies in prison and challenge the current status of women within criminal justice systems who are mothers of young infants.

This article is significant in its advocacy of using a theoretical approach that emphasises the benefits of using legislation, including international human rights frameworks. The premise of Therapeutic Jurisprudence (TJ) is that law influences emotional life and psychological well-being (Winick \& Wexler, 2003). With this approach, legal values and due process are not under-mined but used so that the therapeutic effect of legislation is maximised, and the anti-therapeutic effect is minimised (Spencer, 2014). Central to the theoretical framework of TJ is the intricate relationship between the design of legislation and its application. This article will explain the usefulness of $\mathrm{TJ}$ for promoting international legislation relevant for babies in prison as well as exploring how this makes it possible to change the current status quo.

\section{The Invisibility of Babies in Prison}

There is an international consensus that babies can be accommodated by prisons to live with their mothers from new-born. This situation appears to be settled; however, their existence is invisible and to some it could be "unthinkable" to have babies in prison (Crewe, 2020 (a). The first known baby in prison was Henry Kable Junior (born in Norwich Castle Gaol (England) in February 1786), he lived with his mother in Norwich Castle Gaol until he and his parents were all transported to Australia. Currently babies are accommodated by prisons, however their conditions have remained unchanged for over 200 years.

Internationally there is no accurate data relating to the number of babies born in prison or dependent infants with their mothers; even though babies have always been accommodated by female prisons around the world. In fact, Norway is the only country that does not allow new-borns or children in prison (Crewe, 2020 (b). In Norway research has identified that there is a culture where substance-addicted 
women are generally not trusted to take care of their children (Soderstrom and Skoldbekkn, 2012). In Germany young children can legitimately live with their mother in prison until the age of six, and in India children up to this age are imprisoned with their mothers without any pre-school education (Crewe, 2020 (c).

It is difficult to measure the levels of punitiveness across the world for pregnant women or babies in prison. Coercion is known to have impacted the choices and access of services for women, especially with pregnancy and childbirth. Literature and research highlights, the treatment of pregnant women, how they are unsupported with the process of pregnancy, birth and there is a risk of babies dying in childbirth (Abbot el al, 2020). In particular, the dominant theme throughout literature relating to pregnant women relates to their poor conditions and implicitly suggests that prisons are not suitable for this population (Abbot et al, 2020; Chatten, 2013).

There is a dearth of literature about the effects on babies living in mother and baby units. Research has identified that the conditions in prison affects the developmental progress of babies (Birtsch and Rosenkranz, 1988; Catan, 1989; Gimenz-Salinas, 1988). All authors describe conditions within prison as being restrictive in terms of movement, limited materials or toys and no wide-ranging daily activities, spaces, or social experiences (Jimenez and Palacios, 2003).

\section{The Potential of Therapeutic Jurisprudence}

All prisoners have enforceable human rights, which protect them against cruel, inhuman or degrading treatment or punishment. The Universal Declaration of Human Rights (1948), and the Vienna Declaration and Program of Action (1993), states that the foundation of freedom, justice and peace means recognising the inherent dignity and inalienable rights of all individuals (Birgden \& Perlin, 2009). International human rights for all prisoners are safeguarded through covenants such as the Convention Against Torture and Other Cruel Inhuman or Degrading Treatment or Punishment (1987) which gives freedom from torture or cruel, inhuman or degrading treatment. This universal legislation, in conjunction with regional and domestic legislative frameworks must guide the work of activists, practitioners and other stakeholders to support the human rights of people in detention.

The TJ approach promotes an insight about how the law is lived and with law in action. It is possible for legislation (including international human rights) to be designed so that it can minimize anti-therapeutic consequences. In particular, antitherapeutic conditions have been recognised within the United Nations Rules for the Treatment of Women Prisoners and Non-Custodial Measures for Women Offenders (Bangkok Rules, 2010). The Bangkok Rules are unique because they protect the rights of women and are the first international instrument devoted to addressing the needs of children in prison with their parent.

Officially, her Royal Highness Princess Bajrakityapha of Thailand initiated the Bangkok Rules (2010). For some activists and scholars who use a women's rights perspective, the Bangkok Rules 2010 have given hope for the improving prison regimes around the world and potential to improve the rights of female prisoners 
(Barberet, 2014; Carlen, 2013; Cain, 2015; Van-Gundy et al, 2013). They were created using evidence of victimisation of women in prison, covert abuse such as the restrictions of healthcare access, and evidence of revoked visits for women within the prison setting (Van-Gundy et al, 2013). Whilst there is potential for creating an enabling environment for women to access their rights, some women's rights activists have had concerns relating to the legal form of the Bangkok Rules (2010), language used and these rules could be easy to defeat (Barberet, 2014; Gullberg, 2013; Pate and Kilroy, 2010).

The Bangkok Rules (2010) are classified as international non-state legislation, which is often referred to as soft law. Whilst there is no legally binding authority for states to implement this legislation, advocates explain that soft law today can become hard law tomorrow (Dupuy, 1991). The shape and contours of the Bangkok Rules (2010) are unique because there is no legal enforcement for them to be incorporated into local contexts and practice. Whilst the Bangkok Rules (2010) are not enforceable and could be regarded by lawyers as soft law, these rules are significant with their provision of explicit protection for women in criminal justice systems around the world. There have been concerns about the compliance of states which have ratified the Bangkok Rules (2010) and very little research about their implementation (Barberet, 2014; Van Gundy and Bauman-Grau, 20103; Walby, 2011).

The focus for research, campaigners and activism has conventionally sought to change domestic interpretations of the law, sentencing decisions and encourage appeals. For example, within England and Wales, a new study will be exploring why pregnant women have been sentenced to prison and their experiences of incarceration (Brown and Epstein, 2020). Whilst sentencing decisions are an important factor for understanding the topic of babies in prison, this focus is unlikely to change the status quo because sentencing depends on the infrastructure of a criminal justice system and wider societal values. Moreover, it is important to recognise the extent activists, practitioners and other stakeholders can be involved with reducing the numbers of babies in prison and discussing alternatives to imprisonment.

\section{Mainstreaming Therapeutic Jurisprudence}

The International Society for Therapeutic Jurisprudence currently promotes the philosophy and practice of examining the therapeutic and anti-therapeutic properties of laws, public policies and legal institutions. The intention is to support interdisciplinary scholars and professional or judicial practices to promote therapeutic jurisprudence in the mainstream. The methodology suggested by Wexler (2014) takes into account how influences on legal actors are different and metaphorically explains these as vineyards. Understanding influences on legal actors is particularly important for examining the potential of $\mathrm{TJ}$ for encouraging the implementation of the Bangkok Rules (2010).

The broad scope of TJ is useful for explaining the extent this philosophy could facilitate the implementation of the Bangkok Rules (2010), which are clear in their prescription that custody should be a last resort for pregnant women and their dependent children. Traditionally TJ has been advocated for the application of domestic legislation; 
however other studies have explained how a range of stakeholders such as forensic psychologists could relate to TJ through applying other forms of law such as professional ethical codes (Dickie, 2008, Birgden and Perlin, 2009) or human rights (Birgden, 2015; Birgden and Cucolo, 2011; Birgden and Perlin, 2008; Perlin, 2015, Winick, 2002).

If stakeholders such as judges, lawyers, mental health professionals, probation officers as well as correctional staff could acknowledge their position as duty bearers then this would facilitate implementation strategies that will support offender rights using a humanistic approach. The Bangkok Rules (2010) have been designed to minimize the anti-therapeutic consequences for women and their young children, however in reality the application of this legislation is difficult. It is known that international human rights frameworks have shifted from a safety net for the protection of prisoners' rights to an inventory framework against which to measure organisation reputation and the use of procedures (Hannah-Moffat, 2014). Significantly, the duty bearers of the Bangkok Rules (2010) include individuals from non-governmental organisations, local communities and the voluntary sector. The next three sections examine the role of activists who represent the rights of women, practitioners who work in prisons and other potential stakeholders.

\section{The Role of Activists}

Activists are useful for exploring local interpretations, implementation issues and areas for developing future-orientated solutions. Ideally activists could highlight the therapeutic and anti-therapeutic consequences for criminalised women as well as raise awareness about the potential for the Bangkok Rules (2010) improving female prisoners' rights. It is possible that activists could provide an insight, which would benefit the application of TJ principles and these legal actors, could also be involved with influencing or reforming legal structures and local cultures so they are TJ friendly. Activists involved with women in prison often have a dual role by running prison programmes, offering alternatives to imprisonment and providing services, which support well-being through methods such as advocacy (Barberet, 2014).

Ideally activists could highlight the therapeutic and anti-therapeutic consequences for criminalised women as well as raise awareness about the potential for the Bangkok Rules (2010) improving female prisoners' rights. The difficulty is that there are often disagreements with the focus of campaigns for change. The position of prison reformers has been highlighted as part of the problem and often programs for supporting incarcerated mothers and children do not take into account that they are entangled in a state's apparatus of control (Craig, 2009). Struggles exist, however challenges from the margins are often defined as 'irrelevant radicalism', and proponents of alternative ideas are not discussed which further entrenches the existing order (Mathiesen, 2006).

Abolitionist thought remains focused on resistance against ideas and practices that are integral to institutionalised punishment and exclusion. It is asserted that liberalism is often a façade that masks material and power differentials between groups (Whalley and Hacket, 2017). In particular, abolitionists oppose legal pluralism and the imposition of law from a supranational level to national laws 
(Santos, 2002). Whilst TJ could be a useful philosophy, it relies on understanding the usefulness of legislation.

The unique issue for examining international non-state legislation which is relevant for female prisoners concerns the range of potential legal actors. Individuals and organisations involved with activism are duty bearers of the Bangkok Rules (2010) and have an important role for identifying issues relating to the effects of prison rules, domestic, regional and international legislation for women in prison. The work of activist groups does not only relate to the promotion or creation of legislation but also has the potential to create an awareness and name or shame instances where there have been violations of human rights (Risse and Roppe,2013).

\section{The Role of Practitioners}

Whilst practitioners working within the prison setting have potential for improving conditions for prisoners, their responsibility towards implementing $T J$ is not straightforward, especially in relation to international non-state legislation. By reading the Bangkok Rules, (2010) alongside other international non-state legislation such as the Mandela Rules it is possible to understand how this framework compliments a human rights-based approach.

Using the TJ lens means practitioners have a role that is therapeutic rather than antitherapeutic. TJ scholars have encouraged therapeutic practice from practitioners who work in prisons and have made recommendations for specific interventions affecting forensic psychologists (Birgden and Perlin, 2009), parole (Wexler, 2013) or drug rehabilitation programmes (Birgden, 2004). Through their role and responsibilities as therapeutic agents' practitioners have potential for implementing TJ. In order to maximise the therapeutic effects of legislation they will need to work within a culture and correctional setting which is conducive to rehabilitation of offenders (Birgden, 2004).

Mechanisms of support are known to be affected by the prison environment, the role of practitioners as well as the attitudes of women in prison. There could be alternative choices for babies, including having permission to leave their mothers to live in local communities without relying on their mother's prison sentence or live with their mothers on a flexible basis. A major hurdle relating to the taken-for-granted understandings of mother and baby units concerns their imperceptible nature.

\section{The Role of Stakeholders}

A stakeholder can be defined as an individual, group or network of people involved with, or having interests in, or affected by a particular activity (Duke et al, 2014). TJ has the scope to address a full range of legal actors, lawyers, parole officers and corrections professionals (Gal and Wexler, 2015). In relation to the implementation of 
the Bangkok Rules it is possible to identify how other stakeholders such as policymakers, non-governmental organisations or researchers also have a role with the implementation of the Bangkok Rules (2010).

Whilst the Bangkok Rules (2010) have the potential to improve access and rights for female prisoners, stakeholders will need to translate them for local communities and cultures. It has been suggested that translations by stakeholders who are involved with institutions of global governance could be useful because they empower local populations who are politically and economically marginalised (Nash, 2014). There is potential for stakeholders translating international legislation so that it is relevant and understood in local contexts, however, the women's rights perspective criticises the content of international legislation for not being culturally relevant. Policy and practice routinely focus on the impact of imprisonment for women as offenders with infants rather than babies as individuals who will have their own family (including fathers or grandparents), social and community support.

\section{Conclusion}

Little is known about the potential of therapeutic jurisprudence (TJ) for improving the rights of female prisoners. Within this article, consideration has been made of international non-state legislation which has been designed to improve conditions of women in prison. Implicitly anti-therapeutic conditions have been recognised within the United Nations Rules for the Treatment of Women Prisoners and Non-Custodial Measures for Women Offenders (Bangkok Rules, 2010).

The Bangkok Rules are unique because they protect the rights of women and are the first international instrument devoted to addressing the needs of children in prison with their parent. Whilst the Bangkok Rules (2010) are not enforceable and could be regarded by lawyers as soft law, these rules are significant with their provision of explicit protection for women in criminal justice systems around the world.

There are no internationally consistent conditions, agreement on the age of separation or discussion about the possible choices for those who are supporting infants living in mother and baby units. Concerns from scholars and activists using a women's rights perspective relate to how the rights of female prisoners are managed and taken into account within the prison setting. Whilst the introduction of the Bangkok Rules (2010) appear to have given hope that the anti-therapeutic conditions for prisoners could be eradicated, the reality for creating a rights respecting culture in prisons across the globe is complex. 


\section{References:}

Abbot, L, Scott, T, Thomas, $\mathrm{H}$ and Weston, K (2020) Pregnancy and childbirth in English Prisons: institutional ignominy and the pains of imprisonment Sociology of Health and Illness Vol 42: No 3

Barberet, R. (2014) Women, Crime and Criminal Justice: a global enquiry. New York: Routledge

Birgden, A. \& Perlin, M. (2009). "Where the home in the valley meets the damp dirty prison": a human rights perspective on therapeutic jurisprudence and the role of forensic psychologists in correctional settings. Aggression and Violent Behavior, 14, 256-263. doi:10.1016/j.avb.2009.04.002

Birgden, A. (2015). Therapeutic jurisprudence in practice in the correctional system: a multidisciplinary approach. In Aotearoa conference on therapeutic jurisprudence, Weaving strands. N,W, Raranga (2015). Retrieved on 15 March 2016 from http://www.tjaotearoa.org.nz

Birgden, A and Cucolo, $\mathrm{H}$ (2011). The treatment of sex offenders: evidence, ethics, and Human Rights Sexual Abuse: a journal of research and treatment 23 (3), 295 313 doi: $10.1177 / 1079063210381412$

Birgden, A (2004) Therapeutic jurisprudence and responsivity: finding the will and the way in offender rehabilitation Psychology, Crime \& Law, 10:3, 283 - 295 DOI: $10.1080 / 10683160410001662771$

Birgden, A \& Perlin, M (2008) 'tolling for the luckless, the abandoned and forsaked': Therapeutic Jurisprudence and international human rights law as applied to prisoners and detainees by forensic psychologists Legal and Criminological Psychology 13, 231 -243. doi: 10.1348/135532508X281511

Birgden, A. \& Perlin, M. (2009). "Where the home in the valley meets the damp dirty prison": a human rights perspective on therapeutic jurisprudence and the role of forensic psychologists in correctional settings. Aggression and Violent Behavior, 14, 256-263. doi:10.1016/j.avb.2009.04.002

Birtsh V and Rosenkranz, J (1988) Mutter und Kinder im Gefangnis Juventa Verlag: Munich

Brown, G and Epstein, R (2020) Why are Pregnant Women in Prison? Filia https://filia.org.uk/news/2020/6/30/why-are-pregnant-women-in-prison

Cain, C (2015) State of the estate: women in prison's report on the women's custodial estate $2^{\text {nd }}$ edition, accessed 15 March 2016 from http://www.womeninprison.org.uk

Carlen, P (2013) Preface in Carlton, B. and Segrave, M. (2013) Women exiting prison: Critical essays on gender, post-release support and survival. Oxon: Routledge. 
Catan L (1989) 'The development of young children in HMP mother and baby units' working paper in Psychology Series No 1: University of Sussex, 1989.

Chatten, P, (2013). Pregnant and in prison: can the quality of services provided affect the overall perception of being pregnant? Plymouth Law and Criminal Justice Review retrieved April 2013

Craig, S (2009) A Historical Review of Mother and Child Programs for Incarcerated Women the Prison Journal 89: 1

Crewe, H. (2020 (a) When the Pendulum is stuck! - Invisible Agonists and Babies in Prison. Cambridge Open Engage. doi:10.33774/coe-2020-nkn75

Crewe, H. (2020 (b) “No Babies in Prison?” - Norway's Exceptionalism Explained Open Engage

https://www.cambridge.org/engage/coe/article-details/5f94c2a58f3ba900111bdc84

Crewe, H (2020 (c) Putting Babies First - Supportive Choices for Mother and Baby Units Open Engage https://www.cambridge.org/engage/coe/articledetails/5f762c52a70f3600190e51eb

Dickie, I. (2008). Ethical dilemmas, forensic psychology, and therapeutic jurisprudence Thomas Jefferson Law Review 30, 455 -461.

Duke, K. \& Thom, B. (2014). The role of evidence and the expert in contemporary processes of governance: the case of opioid substitution treatment policy in England. International journal of drug policy. 25(2014) 964-971. http://dx.doi.org/10.1016/drugpo.2014.01.015

Dupuy, P (1991) Soft law and the international law of the environment International law of the environment 12: 420-435

Gelsthorpe, L and Hedderman, C (2012) Providing for Women Offenders - The Risks of Adopting a Payment by Results Approach. Probation Journal, December, $59(4)$

General Assembly Resolution 70/175 (2016) United Nations Standard Minimum Rules for the Treatment of Prisoners (the Nelson Mandela Rules)

General Assembly Resolution 45/110 (1990) United Nations Standard Minimum Rules for Non-custodial Measures (The Tokyo Rules) accessed 24 May 2016 from http://www.unodc.org

Gimenez-Salanas, E (1988) Influencia del medi penitenciari sobre el desenvopament psicologic de l'infant. Centre d'Estudis I Formacio Departament de Justica.

Generalitat de Catalunya: Barcelona

Hannah-Moffat, K Sacrosanct or flawed: risk accountability and Gender-responsive penal politics, Current Issues in Criminal Justice. (2010) Vol 22: No 2 
Jimenez, J and Palacios, J (2003) When Home is in Jail: Child Development in Spanish Penitentiary Units. Infant and Child Development 12: 461-474

Kilory, Debbie and Pate, Kim. "Activism Around Gendered Penal Practices". Current Issues in Criminal Justice Vol 22, Issue 2 (2010), 325-343.

Nash, K (2009). The cultural politics of human rights: comparing the US and UK. Cambridge University Press: Cambridge.

Perlin, M (2015) "God said to Abraham/kill me a son": why the insanity defense and the incompetency status are compatible with and required by the Convention on the Rights of Persons with Disabilities and Basic Principles of Therapeutic Jurisprudence, unpublished draft accessed through personal communication with Michael Perlin.

Risse, T and Ropp, S (2013) Introduction and stock-taking in Risse, T; Ropp, S and Sikkink,K (2013) The persistent power of human rights: from commitment to compliance Cambridge: Cambridge University Press

Soderstrom, K and Skoldbekken, J (2012) Pregnancy and substance abuse - the Norwegian :10-3 solution. Ethical and clinical reflections related to incarceration of pregnant women to protect the foetus from harmful substances, Nordic studies on Alcohol and Drugs, Vol 29.

Spencer, P. (2014). From alternative to the new normal: therapeutic jurisprudence in the mainstream retrieved on 15 March 2016 from International Therapeutic Jurisprudence in the Mainstream Project. http://www.mainstreamtj.wordpress.com

United Nations General Assembly, (2011). Resolution adopted by the General Assembly: 65/229 United Nations Rules for the Treatment of Women Prisoners and Non-custodial Measures for Women Offenders (the Bangkok Rules). Sixty-fifth session: agenda item 105.

Van Gundy, A \& Buamann-Grau, A. (2013) Women, incarceration and human rights violations. Farnham, Surrey and Burlington, USA: Ashgate Publishing Company

Walby, S (2011). The future of feminism Cambridge, Polity Press.

Wexler, D (2013) Therapeutic Jurisprudence and the culture of critique accessed April 2016 Journal of Contemporary Legal Issues, 10, 263-277, 1999; Arizona Legal Studies Discussion Paper No. 13-50. SSRN: http://ssrn.com/abstract=1987/89

Wexler, D. (2014). Moving forward on mainstreaming therapeutic jurisprudence: an ongoing process to facilitate the therapeutic design and application of the law. Discussion paper no 15-10 Arizona Legal Studies: The University of Arizona.

Whalley, E and Hackett, C (2017) Carceral Feminisms: the abolitionist project and undoing dominant feminisms Contemporary Justice Review Routedge, Taylor and Francis Group. 
Winick, B (2002). Therapeutic jurisprudence and the treatment of people with Mental IIIness in Eastern Europe: Construing International Human Rights Law. New York Law School Journal International and Comparative Law 21, 537 -572

Winick, B. \& Wexler, D. (2003) Judging in a therapeutic key: therapeutic jurisprudence and the courts. Durham, North Carolina: Carolina Academic Press. 